\title{
Phenolic-driven sensory changes in functional foods
}

\author{
Adriano Costa de Camargo* and Andrés R. Schwember
}

Polos Territoriales Fundación para la Innovación Agraria (FIA), Desarrollo de ingredientes funcionales y aditivos especializados para la valorización de la pequeña y mediana agricultura de secano, Departamento de Ciencias Vegetales, Facultad de Agronomía e Ingeniería Forestal, Pontificia Universidad Católica de Chile, Casilla 306-22, Santiago, Chile

*Corresponding author: Adriano Costa de Camargo, Polos Territoriales Fundación para la Innovación Agraria (FIA), Desarrollo de ingredientes funcionales y aditivos especializados para la valorización de la pequeña y mediana agricultura de secano, Departamento de Ciencias Vegetales, Facultad de Agronomía e Ingeniería Forestal, Pontificia Universidad Católica de Chile, Casilla 306-22, Santiago, Chile. E-mail: adrianoesalq@gmail.com

DOI: $10.31665 / J F B .2019 .5173$

Received: March 01, 2019; Revised received \& accepted: March 25, 2019

Citation: de Camargo, A.C., and Schwember, A.R. (2019). Phenolic-driven sensory changes in functional foods. J. Food Bioact. 5: 6-7.

\begin{abstract}
The functional food, bioactive ingredients and nutraceutical industries are focused primarily on developing and validating the bioactivity of their products. Furthermore, the scientific community is pretty much moving in the same direction. A quick search in the literature demonstrates that phenolic compounds are perhaps the most studied bioactive phytochemicals due to their myriad of health benefits, including antioxidant and anti-inflammatory effects. In fact, due to their role in preventing cardiovascular disease, certain types of cancer, and enzyme inhibition in connection with type 2 diabetes and obesity, phenolic compounds are gaining attention of the industry. However, many phenolic compounds can influence the sensory characteristics of the final product and hence consumer acceptance must be considered. Therefore, in this contribution we summarize the potential sensory effects of phenolic compounds by focusing on their structuctural features.
\end{abstract}

Keywords: Polyphenols; Phenolic acids; Flavonoids; Sensory quality.

Industrial food products should be sensorially accepted by consumers and demonstrate satisfactory shelf-life. Therefore, development of a functional or enriched food should also consider these aspects (de Toledo et al. 2018). An unexpected food color may be the first attribute related to consumers' rejection (de Camargo et al., 2014). Anthocyanins, which are present in high concentrations in several by-products (Ayoub et al. 2016; Garcia-Mendoza et al., 2017; He et al., 2016; Leite-Legatti et al., 2012), are especially susceptible to $\mathrm{pH}$ changes. Therefore, besides the expected color effect from food fortification, $\mathrm{pH}$ changes in the medium may also change the color of anthocyanins present in plant food by-products or their extracts. For example, the appearance and color have been found to be affected by incorporation of peanut skin in peanut butter (Sanders III et al., 2014).

The characteristic bitter taste of several phenolic compounds raises a dilemma for the designers of functional foods because their fortification with plant food by-products, which are rich in these phytochemicals and/or nutrients, may be incompatible with consumer acceptance (Drewnowski and Gomez-Carneros, 2000). Quercetin has been reported to affect the bitterness of food products more than rutin (Suzuki et al., 2015). In the presence of rutinosidase, rutin may be hydrolyzed and generate quercetin and rutinose as final products. Chlorogenic acid lactones, known contributors to coffee bitterness, can also be hydrolyzed by esterases (Kraehenbuehl et al., 2017), thus decreasing their effect on bitterness. Likewise, beta-glucosidase may hydrolyze conjugate isoflavones and liberate their corresponding aglycones (Handa et al., 2014). Furthermore, several phenolics originating via the action of enzymatic (yeast mediated) and chemical reactions during winemaking may also be present in their corresponding by-products (Barcia et al., 2014). As a consequence, the sensory changes in fortified products may not be necessarily attributed to the parent compound (e.g. rutin, conjugated isoflavones, chlorogenic acid lactones) but to their hydrolyzed products. Therefore, a full scan of the phenolic 
profile in the final product subjected to fortification is always recommended rather than just monitoring specific compounds.

Bitter taste has been reported in the use of certain plant byproducts with high proanthocyanidins contents (de Camargo et al., 2014). Highly polymerized proanthocyanidins exhibit greater reactivity towards salivary proteins thus inducing their precipitation and conferring a more pronounced astringency than that of the lower degrees of polymerization (Sarni-Manchado et al., 1999; Sun et al., 2013). Molecular size has been found to be the major factor affecting bitterness and astringency of tannin-containing products (Peleg et al., 1999). Taste receptor cells are characterized by the expression of members of the TASTE 2 Receptor (TAS2R) gene family encoding bitter taste receptors (Soares et al., 2013). According to these latter authors, the $\mathrm{EC}_{50}$ to activate the bitter receptor TAS2R 5 of epicatechin was $\sim 1,000$-fold higher than that of procyanidin trimer when both tannins (pentagalloylglucose and procyanidin trimer) were present in the same micromolar range. Furthermore, the presence of catechol or galloyl group was a critical feature (but not essential) for the interaction of polyphenol compounds with TAS2R5. Roland et al. (2011) also evaluated the sensory effect of isoflavones towards human bitter taste receptors and showed that equol and coumestrol were more bitter than most of the common soybean isoflavones.

Finally, according to the literature (Chillo et al., 2008), especially for the overall quality, spaghetti samples with added buckwheat flour and durum wheat bran, rich in phenolic acids, showed sensorial properties fairly similar to the spaghetti made only of durum semolina, thus demonstrating that a good formulation can overcome the potential detrimental sensory effects in food fortification. The same principle should be considered for the use of phenolics from plant food by-products when attempting to prevent oxidation in food systems. This would most likely be dependent on the structural characteristics of the phenolic compounds present and their required concentration to achieve the set goals in the formulation of the final product.

\section{Acknowledgments}

A.C. de Camargo and A. R. Schwember acknowledges Fondo Nacional de Desarrollo Científico y Tecnológico - FONDECYT postdoctorado (project 3180432) and Fundación para la Innovación Agraria - FIA (Project PYT-2017-0490).

\section{References}

Ayoub, M., de Camargo, A.C., and Shahidi, F. (2016). Antioxidants and bioactivities of free, esterified and insoluble-bound phenolics from berry seed meals. Food Chem. 197: 221-232.

Barcia, M.T., Pertuzatti, P.B., Rodrigues, D., Gómez-Alonso, S., HermosínGutiérrez, I., and Godoy, H.T. (2014). Occurrence of low molecular weight phenolics in Vitis vinifera red grape cultivars and their winemaking by-products from São Paulo (Brazil). Food Res. Int. 62: 500-513.
Chillo, S., Laverse, J., Falcone, P.M., Protopapa, A., and Del Nobile, M.A. (2008). Influence of the addition of buckwheat flour and durum wheat bran on spaghetti quality. J. Cereal Sci. 47: 144-152.

de Camargo, A.C., Vidal, C.M.M., Canniatti-Brazaca, S.G., and Shahidi, F. (2014). Fortification of cookies with peanut skin: Effects on the composition, polyphenols, antioxidant properties and sensory quality. J. Agric. Food Chem. 62: 11228-11235.

de Toledo, N.M.V., de Camargo, A.C., Ramos, P.B.M., Button, D.C., Granato, D., and Canniatti-Brazaca, S.G. (2018). Potentials and pitfalls on the use of passion fruit by-products in drinkable yogurt: Physicochemical, technological, microbiological, and sensory aspects. Beverages, 4: 47.

Drewnowski, A., and Gomez-Carneros, C. (2000). Bitter taste, phytonutri ents, and the consumer: a review. Am. J. Clin. Nutr. 72: 1424-1435.

Garcia-Mendoza, M.P., Espinosa-Pardo, F.A., Baseggio, A.M., Barbero, G.F., Maróstica Junior, M.R., Rostagno, M.A., and Martínez, J. (2017). Extraction of phenolic compounds and anthocyanins from juçara ( $E u$ terpe edulis Mart.) residues using pressurized liquids and supercritical fluids. J. Supercrit. Fluids 119: 9-16.

Handa, C.L., Couto, U.R., Vicensoti, A.H., Georgetti, S.R., and Ida, E.I. (2014). Optimisation of soy flour fermentation parameters to produce $\beta$-glucosidase for bioconversion into aglycones. Food Chem. 152: 56-65.

He, B., Zhang, L.-L., Yue, X.-Y., Liang, J., Jiang, J., Gao, X.-L., and Yue, P.-X. (2016). Optimization of ultrasound-assisted extraction of phenolic compounds and anthocyanins from blueberry (Vaccinium ashei) wine pomace. Food Chem. 204: 70-76.

Kraehenbuehl, K., Page-Zoerkler, N., Mauroux, O., Gartenmann, K., Blank, I., and Bel-Rhlid, R. (2017). Selective enzymatic hydrolysis of chlorogenic acid lactones in a model system and in a coffee extract. Application to reduction of coffee bitterness. Food Chem. 218: 9-14.

Leite-Legatti, A.V., Batista, Â.G., Dragano, N.R.V., Marques, A.C., Malta, L.G., Riccio, M.F., Eberlin, M.N., Machado, A.R.T., de Carvalho-Silva, L.B. Ruiz, A.L.T.G., de Carvalho, J.E., Pastore, G.M., and Maróstica Junior, M.R. (2012). Jaboticaba peel: Antioxidant compounds, antiproliferative and antimutagenic activities. Food Res. Int. 49: 596-603.

Peleg, H., Gacon, K., Schlich, P., and Noble, A.C. (1999). Bitterness and astringency of flavan-3-ol monomers, dimers and trimers. J. Sci. Food Agr. 79: 1123-1128.

Roland, W.S.U., Vincken, J.P., Gouka, R.J., Van Buren, L., Gruppen, H., and Smit, G. (2011). Soy isoflavones and other isoflavonoids activate the human bitter taste receptors hTAS2R14 and hTAS2R39. J. Agric. Food Chem. 59: 11764-11771.

Sanders III, C.T., DeMasie, C.L., Kerr, W.L., Hargrove, J.L., Pegg, R.B., and Swanson, R.B. (2014). Peanut skins-fortified peanut butters: Effects on consumer acceptability and quality characteristics. LWT Food. Sci. Technol. 59: 222-228.

Sarni-Manchado, P., Cheynier, V., and Moutounet, M. (1999). Interactions of grape seed tannins with salivary proteins. J. Agric. Food Chem. 47: 42-47.

Soares, S., Kohl, S., Thalmann, S., Mateus, N., Meyerhof, W., and de Freitas, V. (2013). Different phenolic compounds activate distinct human bitter taste receptors. J. Agric. Food Chem. 61: 1525-1533.

Sun, B., Sá, M., Leandro, C., Caldeira, I., Duarte, F.L., and Spranger, I. (2013). Reactivity of polymeric proanthocyanidins toward salivary proteins and their contribution to young red wine astringency. J. Agric. Food Chem. 61: 939-946.

Suzuki, T., Morishita, T., Mukasa, Y., Takigawa, S., Yokota, S., Ishiguro, K., and Noda, T. (2015). Breeding of 'Manten-Kirari', a non-bitter and trace-rutinosidase variety of Tartary buckwheat (Fagopyrum tataricum Gaertn.). Breed. Sci. 64: 344-350. 